\title{
Predictive Duty Cycle of Maximum Power Point Tracking Based on Artificial Neural Network and Bootstrap Method for Hybrid Photovoltaic/ Wind Turbine System Considering Limitation Voltage of Grid
}

\author{
Feby Agung Pamuji \\ Department of Electrical Engineering \\ Institut Teknologi Sepuluh Nopember \\ Surabaya, Indonesia \\ feby@ee.its.ac.id \\ Hery Suryoatmojo \\ Department of Electrical Engineering \\ Institut Teknologi Sepuluh Nopember \\ Surabaya, Indonesia \\ suryomgt@ee.its.ac.id
}

\author{
Nurvita Arumsari \\ Department of Marine Engineering \\ Politeknik Perkapalan Negeri Surabaya \\ Surabaya, Indonesia \\ arum.up3d@gmail.com
}

\author{
Mochamad Ashari \\ Department of Electrical Engineering \\ Institut Teknologi Sepuluh Nopember \\ Surabaya, Indonesia \\ ashari@ee.its.ac.id \\ Soedibyo \\ Department of Electrical Engineering \\ Institut Teknologi Sepuluh Nopember \\ Surabaya, Indonesia \\ soedieb@ee.its.ac.id
}

\begin{abstract}
In this paper, we propose the new control-based the neural network and bootstrap method to predict the duty cycle for the maximum power point of hybrid Photovoltaic (PV) and Wind Turbine generator system (WTG) connected to $380 \mathrm{~V}$ grid. The neural network is designed to be controller by learning the data control of multi-input DC/ DC converter. The artificial neural network (ANN) needs many data for training then the ANN can give the predictive duty cycle to multi input DC/ DC converter. To get more data, we can use the bootstrap method to generate data from the real data. From Photovoltaic characteristic, there are 344 real data after the data are made by bootstrap method we can get 8000 data. The 8000 data of $P V$ can be used for training artificial neural network (ANN) of PV system. From wind turbine characteristic we can get 348 real data after the data are made by bootstrap method we can get 6000 data. The 6000 data of WT can be used for training artificial neural network of WT system. This new control has two responsibilities, are to shift the voltage of PV and WTG to optimum condition and to maintain the stability of grid system. From the simulation results those can be seen that the power of hybrid PV / WTG system using MPPT controller is in maximum power and has constant voltage and constant frequency of grid system.
\end{abstract}

Keywords-neural network, bootstrap, maximum power tracking, stability

\section{INTRODUCTION}

Nasif Mahmud, et al., Integration of renewable energy sources (RES) into traditional power system is one of the most viable technologies to meet the ever- increasing energy demand efficiently. But, this technology arises a lot of challenges that are necessary to be taken care of or smooth operation of the network. Voltage regulation is the most significant technical challenge that tends to limit the amount of penetration of renewable distribution generators (DGs) into the distribution network [3].
Originally mainly devoted estimating the standard deviations, confidence intervals, and bias of the studied statistic. This technique is useful in a wide variety of statistical procedures. However, its use for hypothesis testing, when the data structure is complex, is not straight forward and each case must be mainly treated [4].

Determination of the fault location distribution system usually uses a ground fault detector (GFD) that is installed at each substation. But the installation must be in each substation to find out the location of fault. In this article, the location of fault can be detected by simply installing this fault locator at the starting base of distribution system, so the cost can be saved as result of the installation of GFD at each substation.

Mohammad Hemmat Esfe, et al, propose on designing an artificial neural network which can predict thermal conductivity and dynamic viscosity of ferromagnetic nanofluids from input experimental data including temperature, diameter of particles, and substantial volume fraction. The experimental data were extracted and they were used as learning data set to train the neural network. To find a proper architecture for network, an iteration method was used. Based on the results, there was no overfitting in designed neural network and the neural network was able to track the data [5].

Y.-M. Chen, et al., propose a novel multi-input inverter for the grid-connected hybrid photovoltaic (PV) and wind turbine system to simplify the power system and reduce the cost. The proposed multi-input inverter consists of a buck/buck-boost fused multi-input dc-dc converter and a full-bridge dc-ac inverter. The output power characteristics of the PV array and the wind turbine are introduced. The perturbation and observation control method is used to accomplish the maximum power point tracking algorithm for input sources. The perturbation and observation control method can not maintain the stability 
of grid system because the hybrid system always transfers maximum power to the grid system without knowing the grid system need power or not, that can occur overvoltage if the grid system does not need power[2].

In this paper, we proposed the control method of multi-input inverter for the 380 volt grid-connected hybrid photovoltaic system (PV) and wind turbine generator system (WT) based on artificial neural network and bootstrap method to get maximum power point of the hybrid PV and WT system. We use bootstrap method to generate more data from plotting characteristic of renewable energy for learning ANN because to plot the enough data is difficult from simulation model. This control has some parameters such as delta voltage, delta voltage is the difference between actual voltage and optimum voltage and the weather condition (Irradiance and Wind Velocity). The delta voltage is for knowing the power of hybrid system and the grid system condition that the grid system needs energy or not. If the hybrid system transfers maximum energy to the grid when the grid does not need much energy, it causes over voltage in the grid system. By knowing the weather condition (irradiance and wind velocity), we can design the proper controller based on the weather condition of the wind turbine and photovoltaic environment

\section{PRoblem StATEMENT AND PRELIMINARIES}

\section{A. Hybrid System}

Hybrid system is a merger of two or more renewable energies in order to improve reliability. In this paper is proposed hybrid PV/WTG system that is connected to 380 volt grid. The hybrid PV/WTG system helps the grid to fulfill the electricity demand. Fig. 1 shows the hybrid PV/WTG system.

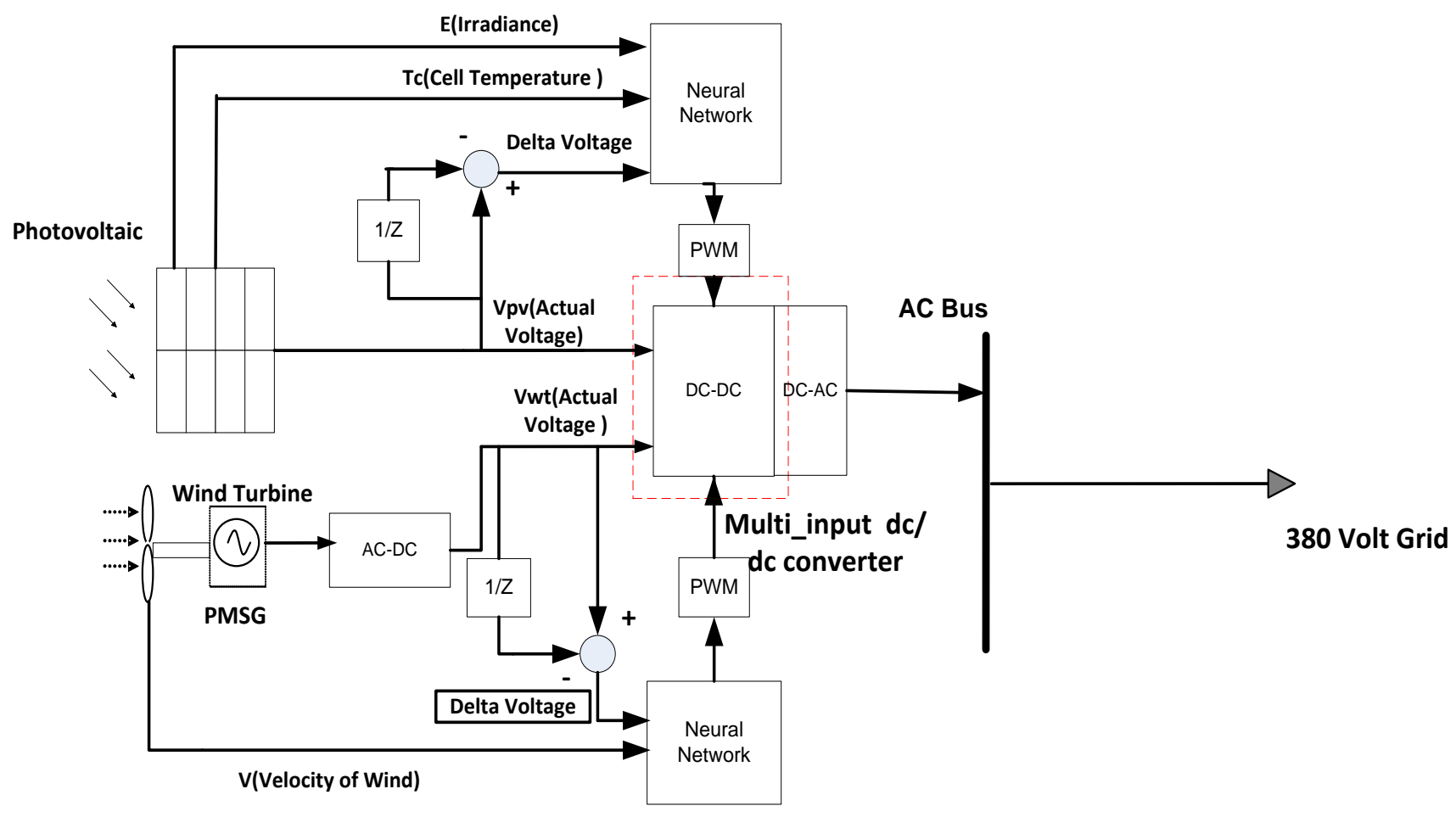

Fig. 1. Hybrid PV/WT system

Power from PV and is WT regulated by multi input dc $/ \mathrm{dc}$ converter and transfered to the $380 \mathrm{~V}$ grid. The multi input $\mathrm{dc} / \mathrm{dc}$ converter is controlled by two controllers based on artificial neural network(ANN) and bootstrap method. The two controllers control multi input dc /dc converter to shift the voltage of hybrid PV/WTG system to get the maximum power. The voltage shifting of the PV and WTG will stop when the delta voltage almost zero, that indicates, the grid system does not need the power, after the

\section{1) Photovoltaic System}

Photovoltaic system (PV) is a renewable energy plant that converts sunlight into electrical energy. The current- voltage (I-V) characteristic of a solar cell is given by Eq. (1).

$$
\begin{aligned}
I_{P V}= & n_{p} I_{S C}-n_{p} I_{o}\left\{\exp \left[\frac{q\left(V_{P V}+R_{S} I_{P V}\right)}{A k T n_{S}}\right]-1\right\}- \\
& n_{p} \frac{\left(V_{P V}+R_{S} I_{P V}\right)}{n_{s} R_{S h}}
\end{aligned}
$$

Where $V_{P V}$ and $I_{P V}$ represent the output voltage and current of PV, respectively; $R_{S}$ dan $R_{s h}$ are the series and shunt resistance of the cell; $q$ is the electron charge $\left(1.6 e^{-19} C\right) ; I_{S C}$ is the light-generated current; $I_{o}$ is the reverse saturation current; $A$ is a dimensionless junction material factor; $k$ is the Boltzmann constant $\left(1.3 e^{-23} \mathrm{~J} /\right.$ $K) ; T$ is the temperature $(K) ; n_{p}$ and $n_{s}$ are the number of 
cells connected in parallel and in series, respectively. To design the controller, the characteristic of PV as shown if Fig. 2 is required.

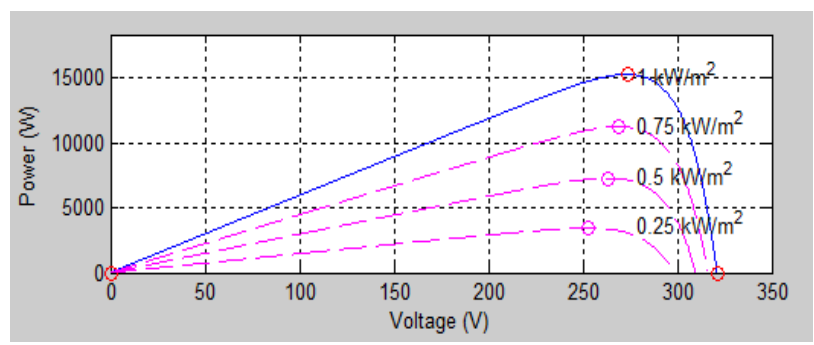

Fig. 2. Characteristic of photovoltaic

From Fig. 2, it can be seen variations of PV power curve by irradiances and the curves have the maximum point of power, the voltage at this point is called the optimum voltage. When PV is not at the optimum voltage, PV can not generate the maximum power. Therefore we need a converter to shift from the actual voltage to the optimum voltage.

\section{2) Wind Turbine}

Wind is moving air that occurs due to uneven heating by the sun to the earth's surface. Air movement can be harnessed for various purposes, such as driving generator through the conversion system with wind turbines. The amount of captured wind power turbine depends on the size of the turbine blades and wind speed, The output power of WTG can be expressed by Eq. (2).

$$
P_{w t}=\frac{1}{2} \pi R^{2} \rho v^{3}
$$

$R$ is the radius of the wind turbine, $\rho$ is the air density and $v$ is the wind speed. To design the controller, it is necessary to be seen the characteristics of the wind turbine as shown in Fig. 3 below.

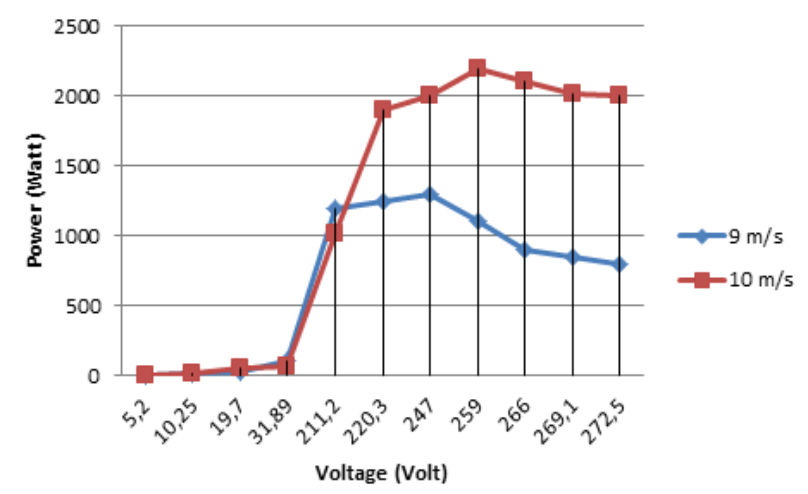

Fig. 3. Characteristic of wind turbine

From Fig. 3, it shows the variation of the power curve depending on wind velocity, The curves have the maximum point of power, The voltage at this point is called the optimum voltage. We need a converter to shift from the actual voltage to the optimum voltage to produce the maximum power.

\section{B. Multi Input DC/DC Converter}

The proposed multi-input dc/dc converter is the fusion of the buck-boost and the buck converter. Syntheses of the multi-input dc-dc converter are done by inserting the pulsating voltage source of the buck converter into the buck-boost converter. In order not to hamper the normal operation of the buck-boost converter and to utilize the inductor for the buck converter, the pulsating voltage source of the buck converter must be series-connected with the output inductor.

Base on the conduction status of the switches $M 1$ and $M 2$, the multi-input dc-dc converter has four operation modes. Fig. 4 (a) through (d) show the equivalent circuits for Mode I through Mode IV, respectively. When switches $M_{1}$ or $M_{2}$ are turned off, diodes $D 1$ and $D 2$ will provide a free-wheeling path for the inductor current. If one of the voltage sources is failed, the other voltage can still provide the electric energy, normally. Therefore, it is very suitable for renewable energy applications.

The input-output voltage relationship can be derived from the steady-state volt-second balance analysis of the inductor. If $M_{1}$ has longer conduction time than $M_{2}$ has, then the equivalent operation circuit for one switching cycle will follow the sequence of Mode I, Mode III, and Mode IV. On the other hand, if $M_{2}$ has longer conduction time than $M_{I}$ has, the sequence becomes Mode II, Mode III, and Mode IV. In either case, the output voltage can be expressed as:

$$
V_{D C}=\frac{d_{1}}{1-d_{2}} V_{P V}+\frac{d_{2}}{1-d_{2}} V_{W i n d}
$$

where $d_{1}$ and $d_{2}$ are the duty ratio of switches $M_{1}$ and $M_{2}$, respectively. Similarly, the average input and output current can be obtained:

$$
\begin{aligned}
& I_{1}=\frac{d_{1}}{1-d_{2}} I_{0} \\
& I_{2}=\frac{d_{2}}{1-d_{2}} I_{0}
\end{aligned}
$$

From the above derived steady-state voltage and current equations, different power distribution demands of the multi-input dc/dc converter can be achieved.

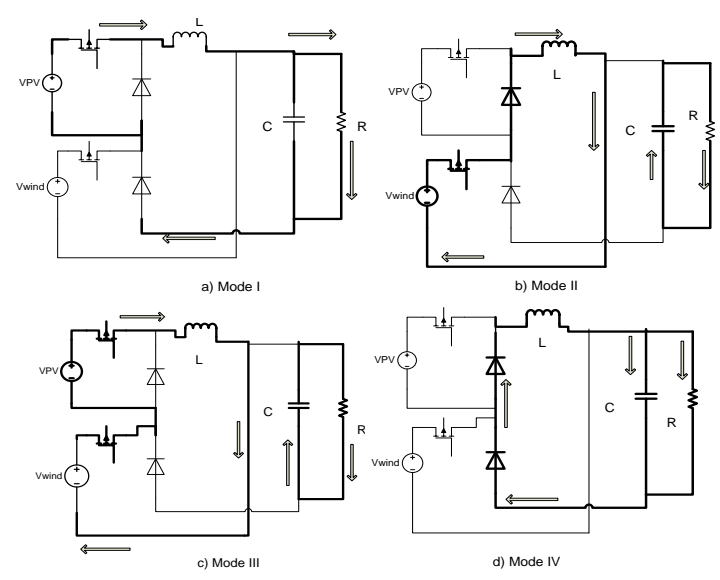

Fig. 4. Equivalent circuits for multi input dc/dc converter [1, 2] 


\section{Control System}

1) The Proposed Maximum Power Point Controller Method

In former maximum power point tracking method the voltage of PV and WT always shift to optimum voltage, this condition can occur increasing voltage and frequency in grid system, because the PV and WT always transfer maximum power to grid wihout knowing the grid demand. In this new proposed MPPT controller method, the controller shifts the voltage of PV and WT step by step, when the controller shifting the voltage of PV and WT if the power that transfered by PV and WT to grid is enough then the controller will stop shifting voltage of PV and WT, To detect when we stop the controller shifting the voltage of PV and WT, we use delta voltage parameter, delta voltage is defferential voltage that indicates there difference voltage between the voltage of inverter and grid. The controller will stop shifting the voltage of PV and WT when the delta voltage zero or near zero.

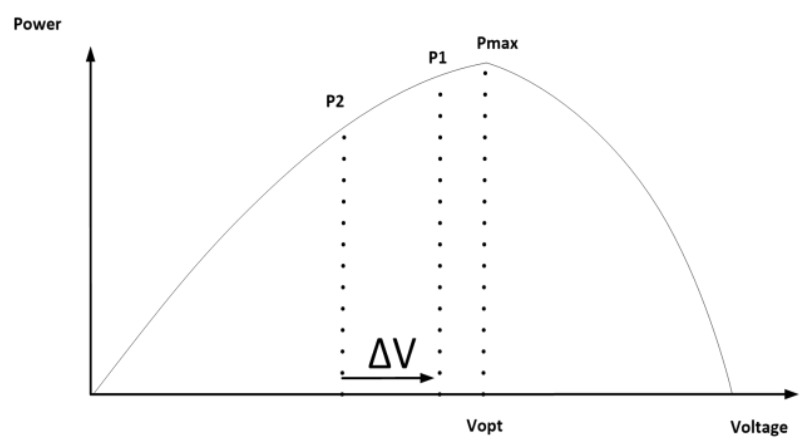

Fig. 5. The proposed maximum power point method [1]

From Fig. 5. The proposed maximum power point method is to shift step by step the voltage of PV and WT, the voltage will be shift until P2, if the power of grid is enough the the controller will stop to shift the voltage but if that is not enough then the controller will shift the voltage until the power output in P1 or Pmax, using this method, we can get the maximum power of hybrid system and stability of the grid system.

\section{2) Data Set for Training ANN}

From the equation 3 and the proposed maximum power point method, we can calculate the data for training ANN. From Photovoltaic characteristic we can get 348 real data, after the data are generated by bootstrap method we can get 8000 data. The 8000 data of PV can be used for training artificial neural network (ANN) of PV system. From wind turbine characteristic we can get 348 real data, after the data are generated by bootstrap method we can get 6000 data. From the PV and WT characteristic data, we used $70 \%$ data for training, 15\% Validation, and testing $15 \%$ ANN.

\section{Artificial Neural Network}

Artificial neural network can be used to predict the duty cycle to ignite multi input DC / DC converter in order to shift the actual voltage to the optimum voltage so that the hybrid system can produce maximum power. In this paper we consider two controllers based ANN, for ANN governing photovoltaic, ANN has three inputs, namely irradiance, temperature cell and delta voltage, while for governing wind turbine, ANN has two inputs, namely wind velocity and delta voltage. Before ANN used that ANN must be trained with simulation data, in this paper the process of training using Levenberg-Marquardt.

Architecture of ANN that used in this research is feed forward networks. The feed forward networks consists of 3 inputs, 1 hidden layer (10 hidden neurons), 1 output layer and 1 output for ANN of PV and consists of 2 inputs, 1 hidden layer (10 hidden neurons), 1 output layer and 1 output for ANN of WT we can see in Figure 6 and 7.

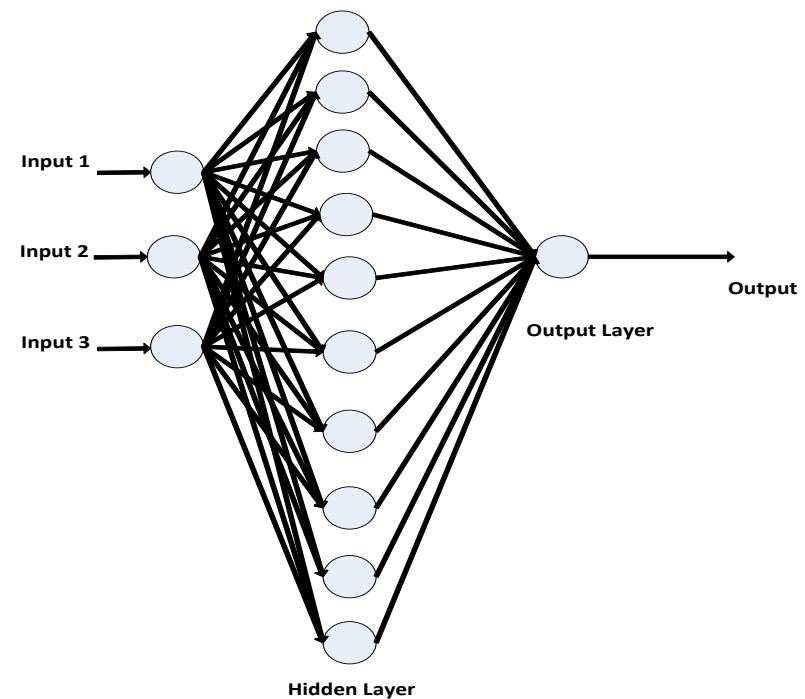

Fig. 6. Architecture of ANN of PV

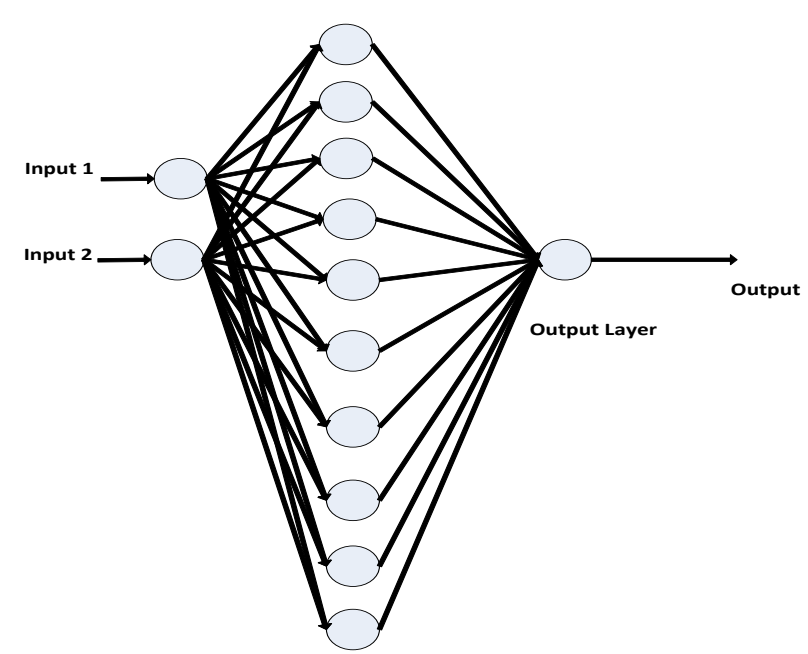

Hidden Laye

Fig. 7. Architecture of ANN of WT

\section{E. Bootstrap}

Statistical science is the science of learning from experience. Efron and Tibshirani (1993) say "Most people are not natural-born statisticians. Left to our own devices we are not very good at picking out patterns from a sea of noisy data. To put it another way, we are all too good at 
picking out non existing patterns that happen to suit our purposes."

Suppose we find ourselves in the following common data-analytic situation: a random sample $x=\left(x_{1}, \ldots, x_{n}\right)$ from an unknown probability distribution $F$ has been observed and we wish to estimate a parameter of interest $\hat{\theta}=t(F)$ on the basis of $x$. For this purpose, we calculate an estimate $\hat{\theta}=s(x)$ from $x$.

A common estimate is the plug-in estimate $t=(\widehat{F})$ where $\hat{F}$ is the empirical distribution defined by

$$
F(x)=\frac{\text { number of values in } X \text { equal to } x}{n}
$$

A bootstrap sample is generated in the following way, For some data $y$ use some procedure to obtain an estimate $\widehat{F}$ of some estimand (in this case the regression function $F$ ), Obtain residuals,

$$
\hat{\varepsilon}=y-\widehat{F}
$$

Take a simple random sample of size $B$ from the residuals $\hat{\varepsilon}_{1}, \ldots, \hat{\varepsilon}_{n}$ Construct a new data set,

$$
y^{*}=\widehat{F}+\hat{\varepsilon}^{*}
$$

with $\hat{\varepsilon}^{*}$ the vector of re-sampled residuals.

\section{F. Levenberg-Marquardt and Bootstrap Methods for \\ Training ANN}

In this research, for training ANN, we use levenberg marquardt and bootstrap method.

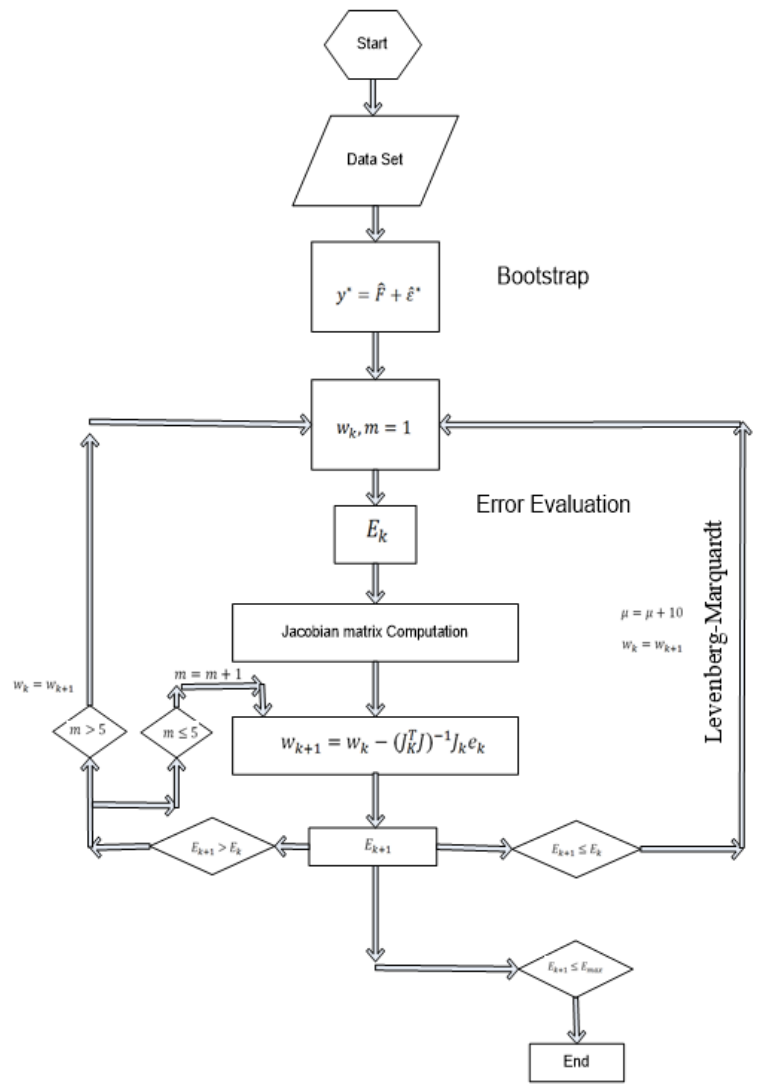

Fig. 8. Levenberg-Marquardt and bootstrap methods for training ANN $[5,6,7,8]$
The data that we obtain from plotting the characteristics of wind turbine and photovoltaic system, we got from generating by the bootstrap method in order to obtain sufficient data for the ANN training process. For training ANN is used the Levenberg-Marquardt method as in Figure 8.

\section{RESULTS}

The artificial neural network (ANN) needs many data for learning then the ANN can give the predictive duty cycle to multi input DC/ DC converter. To get many data we can use the bootstrap method to generate data from the real data. Besides generating data, the bootstrap method is also very useful to derivate strong standart error and confidence interval so it can estimate unbiased and consistent parameter. It can be also used as alternative to estimate parameter when the data don't fulfill assumptions.

From Photovoltaic (PV) characteristic, we can get three input and an output variables. They consist of temperature cell, optimum voltage, irradiance, and Photovoltaic. Each of variable has 86 real data so the total data are 344 . From the PV controller results of learning using Levenberg Marquardt can be obtained as follows:

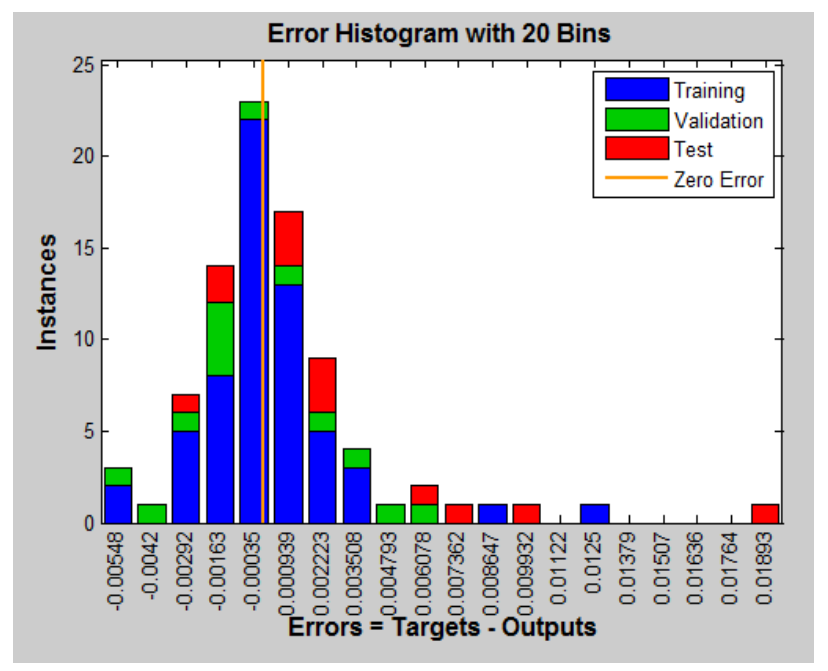

Fig. 9. ANN training error histogram for PV controller using real data

From Figure 9, with 20 bin we know that the errors of $\mathrm{PV}$ data have right skew distribution. Error is the difference between the targets and outputs. It means that the result of the parameters will have bias, so the PV can't be predicted reliably. This is the reason why the bootstrap method is applied. From data in figure 10, Each of characteristic PV data will be generated by bootstrap. By simulating as many as 2000 times, so we can get 8000 total data. The 8000 data of PV can be used for learning artificial neural network (ANN) of PV system. 


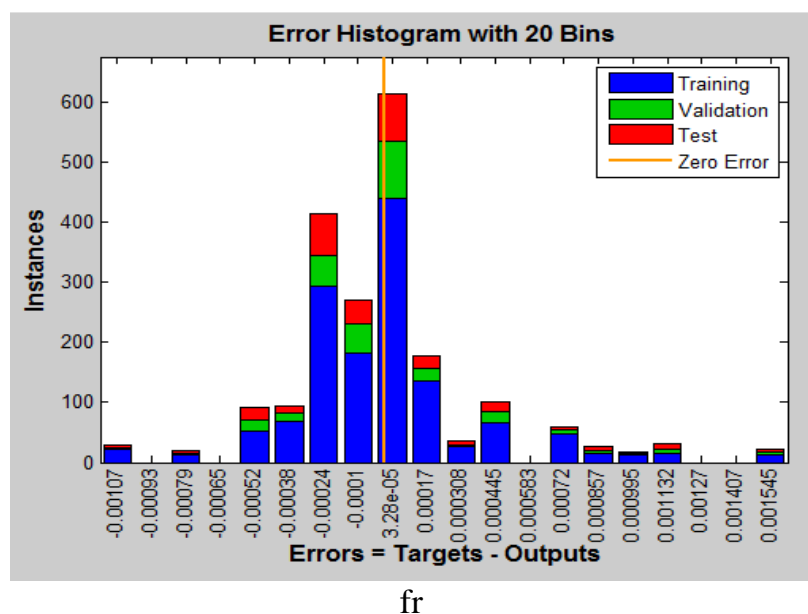

Fig. 10. ANN training error histogram for PV controller using generated data by bootstrap

From Figure 9 and 10, we know that the error PV data from bootstrap better than real data. It is close to normal distribution and more reliable. The error from real data is 0.00035 at instances 20 and from bootstrap is 3.28e-05 at instances 600 .

It is also known that the mean value of real data is 0.66023 , while in the bootstrap method is 0.66134 . So the bias value is -0.00111 . Bias value is the difference between statistic mean of all samples bootstrap and mean of real data. Summary of mean value and standard error from output PV can be seen at Table 1.

TABLE I. BIAS AND STANDARD ERROR FROM OUTPUT PV CONTROLLER

\begin{tabular}{|c|c|c|c|c|c|}
\hline \multirow[t]{2}{*}{ Data } & \multirow{2}{*}{$\begin{array}{l}\text { Real } \\
\text { Data }\end{array}$} & \multirow{2}{*}{$\begin{array}{c}\text { Bootstra } \\
\text { p }\end{array}$} & \multirow[t]{2}{*}{ Bias } & \multicolumn{2}{|c|}{$\begin{array}{c}\text { Confidence } \\
\text { Interval }(95 \%)\end{array}$} \\
\hline & & & & Lower & Upper \\
\hline Mean & $\begin{array}{c}0.6602 \\
3\end{array}$ & 0.66134 & $\begin{array}{c}- \\
0.0011 \\
1\end{array}$ & & \\
\hline $\begin{array}{c}\text { Standar } \\
\text { d } \\
\text { Deviatio } \\
\text { n }\end{array}$ & $\begin{array}{c}0.0890 \\
6\end{array}$ & 0.08926 & $\begin{array}{c}- \\
0.0002\end{array}$ & $\begin{array}{c}0.6580 \\
5\end{array}$ & $\begin{array}{c}0.6646 \\
3\end{array}$ \\
\hline $\begin{array}{l}\text { Standar } \\
\text { d Error }\end{array}$ & $\begin{array}{c}0.0096 \\
0\end{array}$ & 0.00200 & 0.0076 & & \\
\hline
\end{tabular}

From the Table 1 can be seen that standard error PV in bootstrap is smaller than real data. It is caused by the sample number from bootstrap are much greater than real though the standard deviation of real PV is higher. This result is in a small standar error value for bootstrap PV data. Therefore, the results of the statistical test have significant parameters. Using ANN bootsrap data, the most important parameter for PV Controller is optimum voltage with value 0.936 and the second is irradiance with value 0.052 .

The Confidence interval shows the mean estimate parameter from real data. Using bootstrap, the obtained confidence interval has more reliable. As result the estimate mean from real data is between lower 0.65805 and upper 0.66463 with interval $95 \%$.
From error and standard error, that the result of training ANN by using bootstrap data is better than using real data.
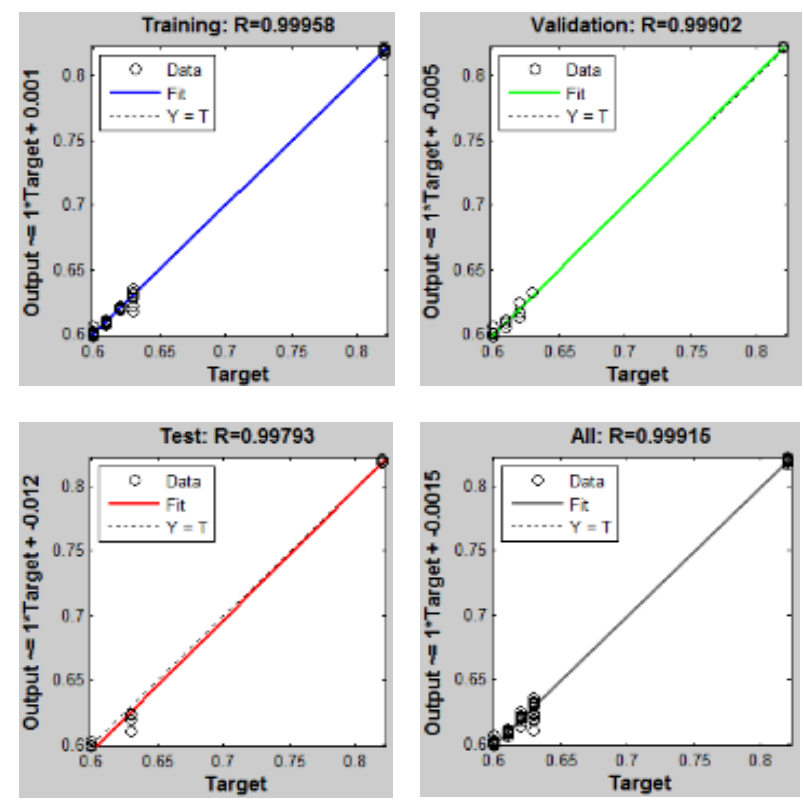

Fig. 11. ANN training regression for PV controller using real data
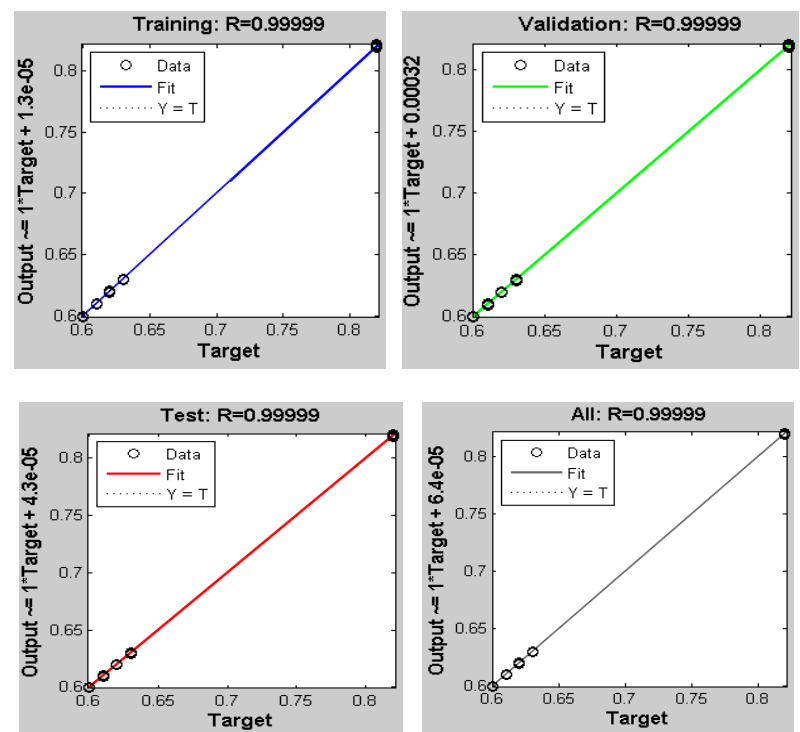

Fig. 12. ANN training regression for PV controller using generated data by bootstrap

Using descriptive analysis, from Fig. 11 can be seen that the distribution of data is not in a straight line while in Fig. 12 shows different condition. In Fig. 12 Distribution data is in a straight line with fit. If analyzed Result from the RSquare, it can be seen that the R-Square from bootstrap with value 0.99999 is better than real data 0.99915 . $R$ squared is a number that indicates the proportion of the variance in the dependent variable that is predictable from the independent variable. The greater R-square number shows the better ANN regression model. So, from RSquare the model is produced by the ANN training using bootstrap data is better than real data.

From wind turbine characteristic, we can get two input and an output variables. They consist of optimum voltage 
and wind velocity. Each of variable has 116 real data so the total data are 348. From the WT controller results of learning using Levenberg - Marquardt can be obtained as follows:

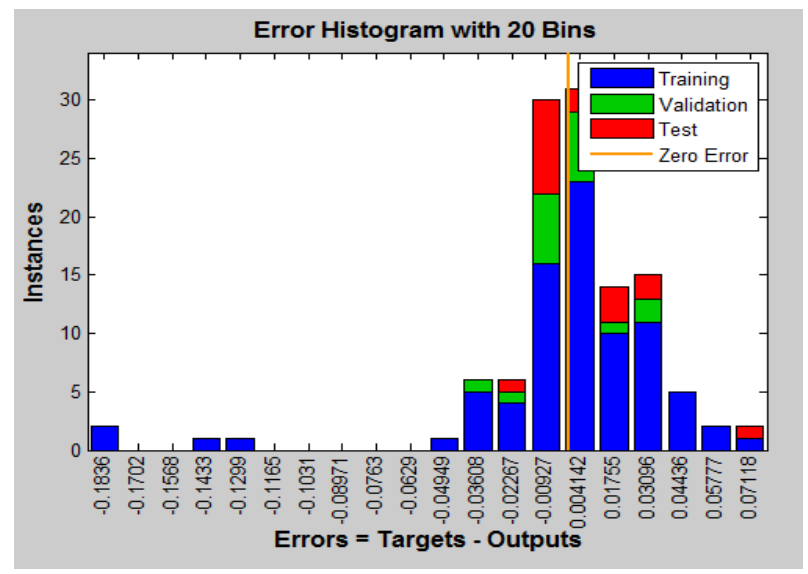

Fig. 13. ANN training error histogram for WT controller using real data

From Figure 13, with 20 bin we know that the errors of WT controller data have left skew distribution. It means that the result of the parameters will also have bias, so the WT can't be predicted reliably. So the bootstrap method will be applied in WT controller too. From data in figure 14, Each of characteristic WT data will be generated by bootstrap. By simulating as many as 2000 times, so we can get 6000 total data. The 6000 data of WT controller can be used for learning artificial neural network (ANN) of PV system.

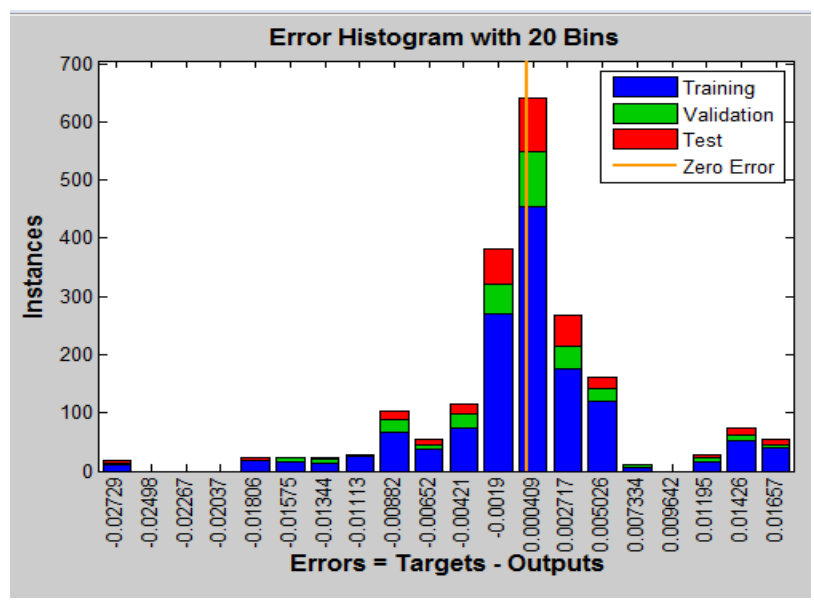

Fig. 14. ANN training error histogram for WT controller using generated data by bootstrap

Same as characteristic on PV, from figure 13 and 14 the error WT controller data from bootstrap is also better than real data. It is almost close to normal distribution and more reliable. The error from real data is 0.004142 at instances 30 and from bootstrap is 0.000409 at instances 630. It is also known that the mean value of real data WT is 0.6727 , while in the bootstrap method is 0.6751 . So the bias value is -0.0024 .

Summary of mean value and standard error from output WT can be seen at Table 2 .
TABLE II. BIAS AND STANDARD ERROR FROM OUTPUT WT CONTROLLER

\begin{tabular}{|c|c|c|c|c|c|}
\hline \multirow{2}{*}{ Data } & \multirow{2}{*}{$\begin{array}{l}\text { Real } \\
\text { Data }\end{array}$} & \multirow{2}{*}{$\begin{array}{l}\text { Boot- } \\
\text { strap }\end{array}$} & \multirow{2}{*}{ Bias } & \multicolumn{2}{|c|}{$\begin{array}{c}\text { Confidence } \\
\text { Interval (95\%) }\end{array}$} \\
\hline & & & & $\begin{array}{l}\text { Low } \\
\text { er }\end{array}$ & $\begin{array}{c}\text { Upp } \\
\text { er }\end{array}$ \\
\hline Mean & $\begin{array}{c}0.672 \\
7\end{array}$ & 0.6751 & -0.0024 & \multirow{3}{*}{$\begin{array}{c}0.67141 \\
5\end{array}$} & \multirow{3}{*}{$\begin{array}{c}0.6 \\
878 \\
5\end{array}$} \\
\hline $\begin{array}{l}\text { Standard } \\
\text { Deviation }\end{array}$ & $\begin{array}{c}0.098 \\
75\end{array}$ & 0.10005 & -0.0013 & & \\
\hline $\begin{array}{l}\text { Standard } \\
\text { Error }\end{array}$ & $\begin{array}{c}0.009 \\
17\end{array}$ & 0.00224 & 0.00693 & & \\
\hline
\end{tabular}

From the Table 2 can be seen that standard error WT in bootstrap is smaller than real data. Therefore, the results of the statistical test have significant parameters. Using ANN bootsrap data, the most important parameter for WT Controller is wind velocity with value 0.603 . The Confidence interval shows the mean estimate parameter from real data. Using bootstrap, the obtained confidence interval has more reliable. As result the estimate mean from real data is between lower 0.671415 and upper 0.678785 with interval $95 \%$. From error and standard error, that the result of training ANN WT Controller by using bootstrap data is better than using real data.
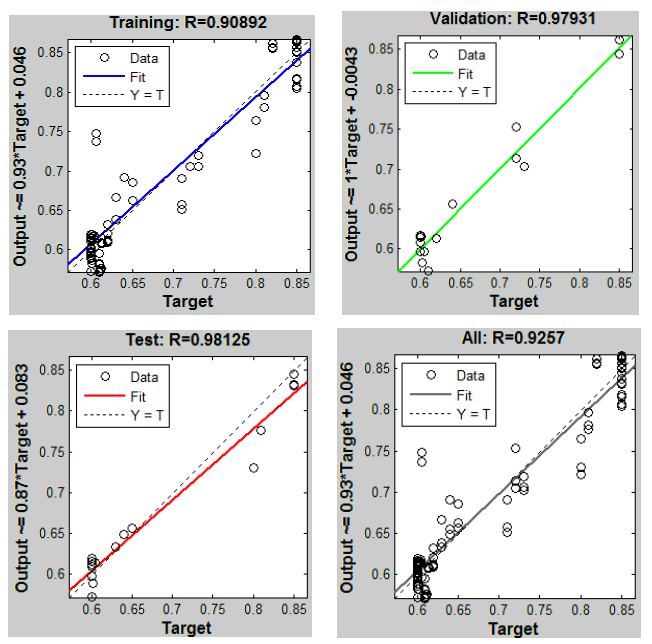

Fig. 15. ANN training regression for WT controller using real data
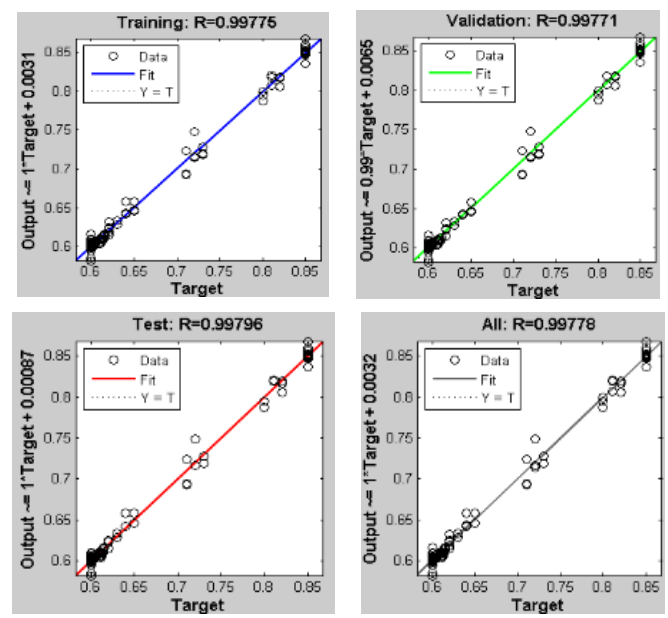

Fig. 16. ANN training regression for WT controller using generated data by bootstrap 
Same as characteristic on PV controller by using descriptive analysis, from Fig.15 can be seen that the distribution of data is not in a straight line and some data away from the fit line. While in Fig.16 shows a slightly different condition. In Fig.16 Distribution data is almost overall in a fit line. If analyzed result from the R-Square, it can be seen that the R-Square from bootstrap with value 0.99778 is better than real data 0.9257. So, From WT Controller model shows that the model is produced by the ANN training using bootstrap data is also better than real data.

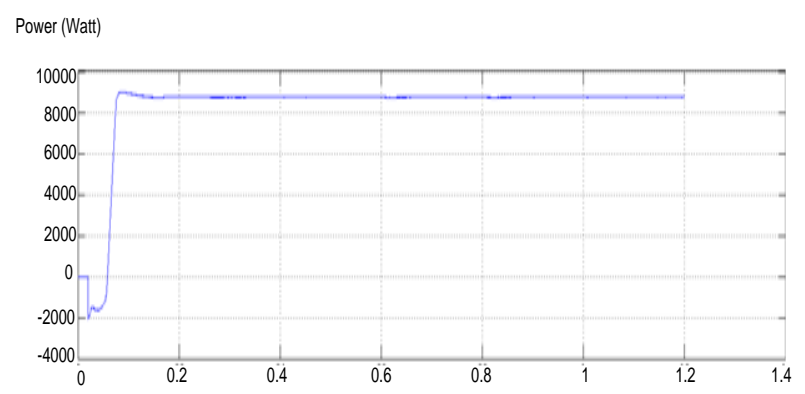

Fig. 17. Power output of hybrid system with ANN controller

From the picture above can be seen that the power generated by the hybrid system using controller-based ANN and bootstrap, generated power at the state maximum $9 \mathrm{~kW}$, because the grid system only requires power $9 \mathrm{~kW}$. If the hybrid system transfers more power from $9 \mathrm{~kW}$, so that can occur over voltage on the grid system. At the starting of the simulation, the inverter can not produce 380 volt, so the power flows from grid to inverter. after 0.05 second, the inverter can produce 380 volt, so the power flows from inverter to grid.

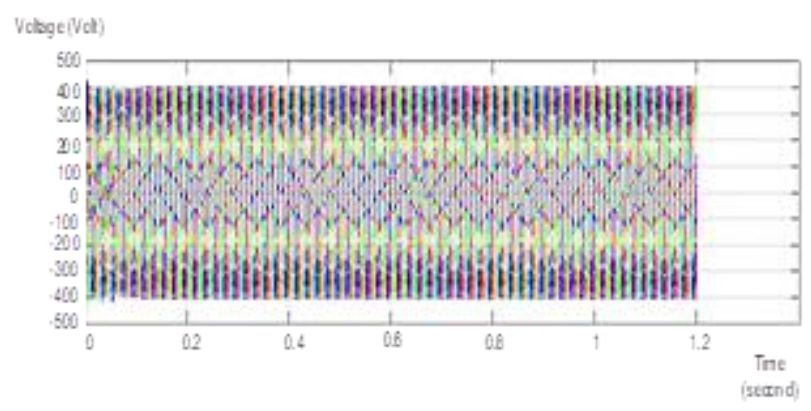

Fig. 18. Output voltage of inverter

From Figure 17 can be Seen that the grid system voltage after transfered Power at $9 \mathrm{~kW}$ can be Constant on $380 \mathrm{~V}$ $\mathrm{AC}$, so the disposal Power of this hybrid system does not interfere with the stability of the grid system.

\section{CONCLUSION}

The ANN before being used to predict the duty cycle must be done the training process using the data characteristics of PV and WT. From training results can be seen that the training using the generated data by bootstrap is better than using real data, because generated data by bootstrap much more than real data and more reliable. The controller based ANN and bootstrap can increase the power output of the hybrid system and also can keep the stability of the grid system.

\section{ACKNOWLEDGEMENTS}

The Author thanks to Institute Teknologi Sepuluh nopember which support to finish this paper.

\section{REFERENCES}

[1] Feby Agung Pamuji, Hajime Miyauchi, "Maximum Power Point Tracking of Multi-input Inverter for connected Hybrid PV/Wind Power System Considering Voltage Limitation in Grid, "International Review on Modelling and Simulations (I.REMOS), Vol.11, No.3, June ,2018

[2] Y.-M. Chen, S.-C Hung, C.-S. Cheng, and Y.-C. Liu, “ Multi Input Inverter For Grid - Connected Hybrid PV/Wind Power System, “ IEEE, 2005.

[3] Nasif Mahmud, A.Zahedi, “ Review of control strategies for voltage regulation of the smart distribution network with high penetration of renewable distributed generation, "Elsevier, 2016

[4] Pablo Martı'nez-Camblor, NorbertoCorral,"A general bootstrap algorithm for hypothesis testing," Elsevier, 2011.

[5] Mohammad Hemmat Esfe, Seyfolah Saedodin, Nima Sina, Masoud Afrand, Sara Rostami, "Designing an artificial neural network to predict thermal conductivity and dynamic viscosity of ferromagnetic nanofluid,"Elsevier, 2015

[6] Amir Abolfazl Suratgar, Mohammad Bagher Tavakoli, and Abbas Hoseinabadi, "Modified Levenberg-Marquardt Method for Neural Networks Training," World Academy of Science, Engineering and Technology International Journal of Computer, Electrical, Automation, Control and Information Engineering Vol:1, No:6, 2007

[7] Hao Yu, Bogdan M. Wilamowski, "Intelligent System," Auburn University, 2010.

[8] Efron B. and Tibshirani, "An Introduction of the Bootstrap". Chapman and Hall/CRC: New York, R.J (1993).

[9] Efron, “The Annals of Statistics", Bootstrap Methods: Another Look At the Jackknife , 7, 1-26, B. (1979).

[10] S. Vinoth John Prakash, P. K. Dhal, "A Review: Solar Tracking System with Grid Used in Kurnool Ultra Mega Solar Park, "International Review of Electrical Engineering (IREE), Vol.14, No.3, 2019.

[11] Abraham Akhikpemelo, Ma-Riekpen J. E. Evbogbai, Michael S. Okundamiya, "Fault Detection on a 132kV Transmission Line Using Artificial Neural Network, "International Review of Electrical Engineering (IREE), Vol.14, No.3, 2019.

[12] Panya Khemmook, Surin Khomfoi, "Transient Stability Improvement Using Coordinated Control of Solar PVs and Solid State Transformers "International Review of Electrical Engineering (IREE), Vol.13, No.6, 2018. 